\title{
Computational Study of $\mathrm{H}_{2}$ binding to $\mathrm{MH}_{3}$ $(\mathrm{M}=\mathrm{Ti}, \mathrm{V}$, and $\mathrm{Cr})$
}

\author{
James J. Hales ${ }^{a}$, Michel L. Trudeau ${ }^{b}$, David M. Antonellic, Nikolas \\ Kaltsoyannis, ${ }^{\text {,* }}$
}

aSchool of Chemistry, University of Manchester, Oxford Road, Manchester M13 9PL, UK

bMaterials Science, Hydro-Quebec Research Institute, 1800 Boul. Lionel-Boulet, Varennes, Quebec, J3X 1S1, Canada

'Department of Chemistry, Lancaster University, Lancaster, LA1 4YB, United Kingdom

\begin{abstract}
A series of amorphous materials, produced by Antonelli et al., based on hitherto elusive early transition metal hydrides $\mathrm{MH}_{3}(\mathrm{M}=\mathrm{Ti}, \mathrm{V}$, and $\mathrm{Cr})$ capable of binding $\mathrm{H}_{2}$ via the Kubas interation, has shown great promise for hydrogen storage applications, approaching US DoE system targets in some cases, even when considerations for the system are taken into account. We here apply quantum chemical computational techniques to study these materials. Starting with monomeric $\mathrm{MH}_{3}(\mathrm{M}=\mathrm{Ti}$, $V$, and $\mathrm{Cr}$ ) we progress to $\mathrm{M}_{2} \mathrm{H}_{6}$ and then penta-metallic systems as representations of the $\mathrm{H}_{2}$ binding sites, analyzing the geometries, energies, $\mathrm{H}_{2}$ vibrational frequencies and binding modes, finding clear evidence of significant Kubas binding. This enables these materials to bind dihydrogen with a binding energy of between 22 and $53 \mathrm{~kJ} \mathrm{~mol}^{-1}$. In agreement with experiment, we conclude that while $\mathrm{TiH}_{3}$ binds $\mathrm{H}_{2}$ exclusively through the Kubas interaction, $\mathrm{VH}_{3}$ and $\mathrm{CrH}_{3}$ additionally physisorb dihydrogen, making these more attractive for practical applications.
\end{abstract}




\section{Introduction}

Hydrogen fuel cells are potential alternatives to the current fossil fuel powered engines that are detrimental to the environment ${ }^{1-4}$. However, the current generation of hydrogen powered vehicles makes use of carbon fibre-based high pressure cylinders that require frequent refuelling ${ }^{5,6}$; although hydrogen is very energy rich by weight the volume required to fuel a vehicle for long distances is prohibitive. For a driving range exceeding $500 \mathrm{~km}$ around $5 \mathrm{~kg}$ of $\mathrm{H}_{2}$ is required; this needs a carbon fibre cylinder with a volume of around 125 $\mathrm{L}$ when pressurised to $700 \mathrm{bar}^{7}$, adding additional constraints to vehicle design. Hence a more commercially attractive and efficient solution to storing the gas is required to encourage higher rates of adoption of hydrogen powered vehicles.

Materials-based solutions have been proposed to store hydrogen in large quantities ${ }^{8-10}$. In general, these materials can be categorised into three groups depending on the type of interaction they have with dihydrogen. One group, which includes many MOFs, binds hydrogen through physisorption ${ }^{11,12}$; the interaction is weak, with a binding energy of around $10 \mathrm{~kJ} \mathrm{~mol}^{-1}$, which can give promising kinetic properties but requires cryogenic temperatures, $77 \mathrm{~K}$, to store significant amounts of the gas, which generates other problems. By contrast, metal hydrides ${ }^{13,14}$ show much stronger binding interaction with $\mathrm{H}_{2}$ $\left(>50 \mathrm{~kJ} \mathrm{~mol}^{-1}\right.$ ) which leads to greater storage capacities but at the expense of difficulties in extracting the dihydrogen for use. Both physisorption and chemisorption materials have problems with heat management as the gas either readily boils off or is difficult to release. An ideal solution should in principle arise from material-dihydrogen binding with energies between these extremes ${ }^{15-17}$, and a third category of proposed hydrogen storage solutions does indeed meet this requirement. These materials exploit the Kubas interaction ${ }^{18}$, in 
which the $\mathrm{H}_{2} \sigma$ orbital donates electronic density into a metal d orbital and concurrently a second metal d orbital donates electronic density into the $\mathrm{H}_{2} \sigma^{*}$ orbital; analogous to the bonding between d block metal centres and alkenes in the Dewar-Chatt-Duncanson mode ${ }^{19}$. This orbital interaction produces metal- $\mathrm{H}_{2}$ complexes characterised by a weakening and extension of the $\mathrm{H}-\mathrm{H}$ bond.

In recent years there has been an increasing interest in developing materials that exploit the Kubas interaction including, from our labs, those based on hydrazines ${ }^{20}$, hydrazides ${ }^{21}$, doped mesoporous silica molecular sieves ${ }^{22,23}$, and early transition metal alkyl hydride gels $^{24-27}$. The latter have shown considerable promise as novel hydrogen storage materials; $\mathrm{TiH}_{3}, \mathrm{VH}_{3}$, and $\mathrm{CrH}_{3}$ have hydrogen storage capacities of 3.49, 5.80, and 5.08 wt\% under pressure at room temperature, with the potential to be much greater. Raman spectroscopy indicates that these materials bind $\mathrm{H}_{2}$ via the Kubas interaction, although they have surprisingly low adsorption enthalpies as measured by in situ calorimetry considering that the hydrogen binding properties persist at room temperature. Hence to probe further the hydrogen binding properties of these materials we here look towards computational methods, which we have previously found to be very informative in understanding Kubas-based systems ${ }^{27-30}$. We have calculated dihydrogen binding to $\mathrm{MH}_{3}$ monomers and $\operatorname{dimers}(\mathrm{M}=\mathrm{Ti}, \mathrm{V}, \mathrm{Cr})$, as well as to more extended pentameric structures. We find extensive Kubas binding in all metal hydrides, with maximum loading levels and $\mathrm{H}-\mathrm{H}$ stretching frequencies in good agreement with experiment. 


\section{Methodology}

Dispersion-corrected generalised gradient approximation density functional theory (DFT) has been employed throughout this study, combining the PBE functional ${ }^{31,32}$ with Grimme's D3 dispersion corrections ${ }^{33}$ and the $6-311++G^{* *}$ basis set s $^{34-37}$. This approach has been shown by others ${ }^{38,39}$ to provide reasonable geometry, IR and electronic data in benchmarking against $a b$ initio techniques..$^{40-43}$ Both Gaussian 09 revision D. $01^{44}$ and Gaussian 16 revision $A .03^{45}$ have been used to perform the calculations presented herein; we have found that both codes produce the same outputs in test cases.

Spin unrestricted DFT was used throughout. Ti(III), V(III), and $\mathrm{Cr}(\mathrm{III})$ centres were treated with 1, 2, and 3 unpaired electrons (upe) respectively; base structures (i.e. the metal hydrides without added $\mathrm{H}_{2}$ ) with multiple metal centres were considered to have the highest possible number of unpaired metal-based valence electrons.

No constraints were imposed during geometry optimisations, which were performed with the default settings except (i) the integration grid was increased from default to UltraFine (ii) geometry convergence criteria were tightened to a maximum force on an atom of $2 \times 10^{-6}$ a.u., the root mean squared average (RMS) force to $10^{-6}$ a.u. on all the atoms, the maximum displacement of an atom to $6 \times 10^{-6}$ a.u., and the RMS of the displacement to $4 \times 10^{-}$ ${ }^{6}$ a.u for each of the monomeric and dimeric systems along with the pentameric base structures. Systems with $\mathrm{H}_{2}$ bound to the pentamers and those marked in the supplementary information were converged to at least the Gaussian default criteria, with maximum force of $4.5 \times 10^{-4}$ a.u., RMS force to $3 \times 10^{-4}$ a.u. on all the atoms, the maximum displacement to $1.8 \times 10^{-3}$ a.u., and the RMS of the displacement to $1.2 \times 10^{-3}$ a.u. Harmonic vibrational frequency analysis was performed on all optimised systems to confirm the 
calculation has reached a true minimum structure with no imaginary frequencies, and to provide thermal energy corrections to the hydrogen binding energies (HBEs) to yield Gibbs energies.

Throughout this work we have used molecular representations of the $\mathrm{H}_{2}$ binding sites. These can be broken down into the representation of the $\mathrm{MH}_{3}$ base structure and the base structure plus bound $\mathrm{H}_{2}$. The average HBE is calculated by taking the energy of the system loaded with dihydrogen and subtracting the energies of the base structure and the individual $\mathrm{H}_{2}$ molecules; this is then divided by the number of dihydrogen molecules present $n$ to give the average HBE:

$$
H B E=\frac{1}{n}[E(\text { Loaded System })-E(\text { Base Structure })-n E(\text { Dihydrogen })]
$$

The distance $\mathrm{d}_{\mathrm{M}-\mathrm{H} 2}$ is defined as the mean of the distances from the closest metal centre to each atom in the $\mathrm{H}_{2}$ unit.

The maximum $\mathrm{H}_{2}$ loading on the base structures was determined through the following method: $\mathrm{H}_{2}$ was added to the base structures incrementally until further additions had no strong interaction with the base structure. For the $\mathrm{MH}_{3}$ monomers and dimers this point was determined by the orientation of the additional $\mathrm{H}_{2}$; these were considered to be non Kubas binding when there are differences in the two $\mathrm{M}-\mathrm{H}\left(\mathrm{H}_{2}\right)$ distances greater than $0.4 \AA$. For the pentamers a different approach was used; the maximum loading was determined to be the point at which an added $\mathrm{H}_{2}$ was found to be closer to another $\mathrm{H}_{2}$ than to the base structure. This latter approach is that adopted in our recent study of $\mathrm{H}_{2}$ binding to the Mn-based storage material $\mathrm{KMH}-1^{27}$. 


\section{Results and Discussion}

\section{$\mathrm{H}_{2}$ binding to monomers of $\mathrm{MH}_{3}(\mathrm{M}=\mathrm{Ti}, \mathrm{V}, \mathrm{Cr})$}

The initial step towards understanding the dihydrogen binding occurring in these $\mathrm{MH}_{3}$ systems was to probe the interaction between $\mathrm{H}_{2}$ and monomeric $\mathrm{MH}_{3}(\mathrm{M}=\mathrm{Ti}, \mathrm{V}, \mathrm{Cr})$. The latter are all are non-planar, although $\mathrm{VH}_{3}$ has an $\mathrm{H}-\mathrm{V}-\mathrm{H}$ angle of $119^{\circ}$ and so is approaching a trigonal planar geometry. Table 1 contains the hydrogen binding energies and key geometric data for the $\mathrm{MH}_{3}$ systems with a single $\mathrm{H}_{2}$ present, as well as the maximum loading level achieved for each metal hydride.

Table 1. Hydrogen Binging Energies $\left(\mathrm{kJ} \mathrm{mol}^{-1}\right), \mathrm{H}_{2}$ Geometric data $(\AA)$ and Stretching Frequencies $\left(\mathrm{cm}^{-1}\right)$ for $\mathrm{MH}_{3}(\mathrm{M}=\mathrm{Ti}, \mathrm{V}, \mathrm{Cr})$

\begin{tabular}{crrrrrr}
\hline Metal & $\begin{array}{l}\text { Number of } \mathrm{H}_{2} \\
\text { bound }\end{array}$ & Average HBE, $\Delta E$ & Average HBG, $\Delta G$ & $\begin{array}{l}\text { Average } \\
\mathrm{d}_{\mathrm{H}-\mathrm{H}} \mathrm{H}_{2}\end{array}$ & $\begin{array}{l}\text { Average } \\
\mathrm{d}_{\mathrm{M}-\mathrm{H} 2}\end{array}$ & $\begin{array}{l}\text { Stretching } \\
\text { Frequencies }\end{array}$ \\
\hline \multirow{2}{*}{$\mathrm{Ti}$} & 1 & -36.3 & 5.9 & 0.834 & 1.917 & 3044 \\
& 5 & -41.1 & 2.1 & 0.817 & 1.939 & Table 2 \\
\hline \multirow{2}{*}{$\mathrm{V}$} & 1 & -51.8 & -9.2 & 0.810 & 1.839 & 3414 \\
& 4 & -55.0 & -11.2 & 0.829 & 1.850 & Table 2 \\
\hline \multirow{2}{*}{$\mathrm{Cr}$} & 1 & -24.1 & 13.8 & 0.786 & 1.973 & 3761 \\
& $3(4)$ & -48.0 & -5.1 & 0.867 & 1.823 & Table 2
\end{tabular}

At the SCF energy level $(\Delta E)$ each of the systems binds a single dihydrogen in a thermodynamically favourable manner, with the strongest interaction seen for $\mathrm{V}$. All are within the expected range for Kubas binding (20-50 kJ mol-1). The Gibbs energies of the binding (HBG) for a single $\mathrm{H}_{2}$ is favourable only for $\mathrm{V}$, and is much weaker than at the SCF level, with the other systems producing energies suggesting no binding would occur. Indeed, the Gibbs energies are all between 37.9 and $42.6 \mathrm{~kJ} \mathrm{~mol}^{-1}$ less favourable than the SCF energies, unsurprising given the entropic penalty of bringing together two molecules to form one.

The bond length in an isolated $\mathrm{H}_{2}$ molecule is calculated to be $0.752 \AA$. All the $\mathrm{H}-\mathrm{H}$ distances in Table 1 are significantly longer than this; a hallmark of the Kubas interaction. 
The largest extension $\left(0.082 \AA\right.$ ) is seen for a single $\mathrm{H}_{2}$ bound to $\mathrm{TiH}_{3}$, clearly within the range proposed by Kubas (0.05-0.25 $\AA$ ). However, this lengthening does not correlate well $\left(R^{2}=\right.$ 0.19) with the HBEs as $V$, the metal which generates the strongest $\mathrm{H}_{2}$ binding, leads to an $\mathrm{H}$ $\mathrm{H}$ bond extension of only $0.058 \AA$. The geometric feature which best correlates $\left(R^{2}=1.00\right)$ with the binding energies is the distance from the metal centre to the $\mathrm{H}_{2}$ unit; $V$ holds $\mathrm{H}_{2}$ the closest followed by $\mathrm{Ti}$ then $\mathrm{Cr}$. The stretching frequency of the bound $\mathrm{H}_{2}$ correlates inversely and perfectly $\left(R^{2}=1.00\right)$ with $\mathrm{d}_{\mathrm{H}-\mathrm{H}} \mathrm{H}_{2}$ for the singly loaded systems.

$\mathrm{H}_{2}$ binding induces only minor changes in the geometries of the $\mathrm{MH}_{3}$ structures; in all cases when $\mathrm{H}_{2}$ is added the symmetry reduces from $\mathrm{C}_{3 \mathrm{v}}$ to $\mathrm{C}_{\mathrm{s}}$. For the Ti system, figure $1 \mathrm{~A}$, there is a less than $1 \%$ extension in the $\mathrm{Ti}-\mathrm{H}$ bonds. The $2-1-4$ and 3-1-4 $\mathrm{H}-\mathrm{Ti}-\mathrm{H}$ angles are slightly contracted, by $2.5 \%$, and the other $\mathrm{H}-\mathrm{Ti}-\mathrm{H}$ angle, $2-1-3$, is expanded by $1.1 \%$. The $\mathrm{V}$ system, figure $1 \mathrm{~B}$, shows slightly different behaviour; the $\mathrm{V}-\mathrm{H}$ bonds are contracted by $<1 \%$ and the $2-1-3$ and $4-1-3 \mathrm{H}-\mathrm{V}-\mathrm{H}$ angles are contracted, by $3.2 \%$, whereas $2-1-4$ is expanded by $2.2 \%$. The $\mathrm{Cr}$ system, figure $1 \mathrm{C}$, shows the most significant change as the $\mathrm{Cr}-\mathrm{H}$ bond length, 1-3 is extended by $1 \%$ and the other bond lengths extend by $<1 \%$; the $\mathrm{H}-\mathrm{Cr}-\mathrm{H}$ angle, $2-1-4$, increases by $6.3 \%$ and the other two are contracted by $2.8 \%$.

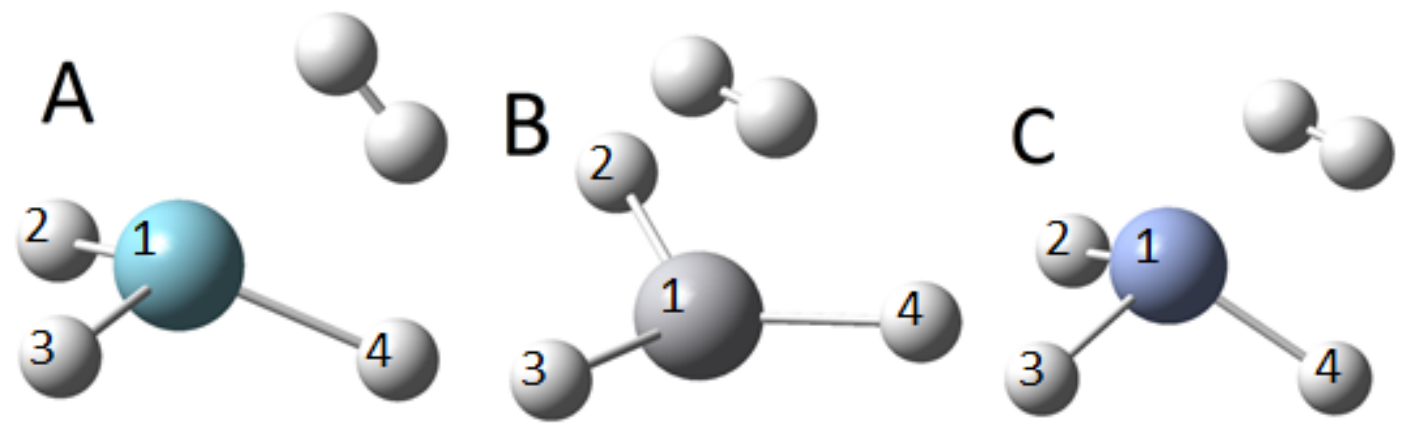

Figure 1. Ball and stick representations of a single $\mathrm{H}_{2}$ binding to the $\mathrm{MH}_{3}$ monomers. $A=\mathrm{TiH}_{3}, \mathrm{~B}=$ $\mathrm{VH}_{3}$ and $\mathrm{C}=\mathrm{CrH}_{3}$. 
In order to verify the presence of the Kubas interaction, we have analysed the molecular structure of the $\mathrm{H}_{2}$ bound systems. The Kohn-Sham molecular orbitals that contribute to the bonding between $\mathrm{H}_{2}$ and $\mathrm{VH}_{3}$ are shown in figure 2; the pertinent orbitals for $\mathrm{Ti}$ and $\mathrm{Cr}$ can be found in the supplementary information figures S1 and S2. There are two orbitals, HOMO-1 and HOMO-3, that show back bonding in which a metal d-orbital interacts with the $\mathrm{H}_{2} \sigma^{*}$ orbital and a third molecular orbital, HOMO-5, which shows the donation from the $\mathrm{H}_{2}$ $\sigma$ orbital into another metal d-orbital.
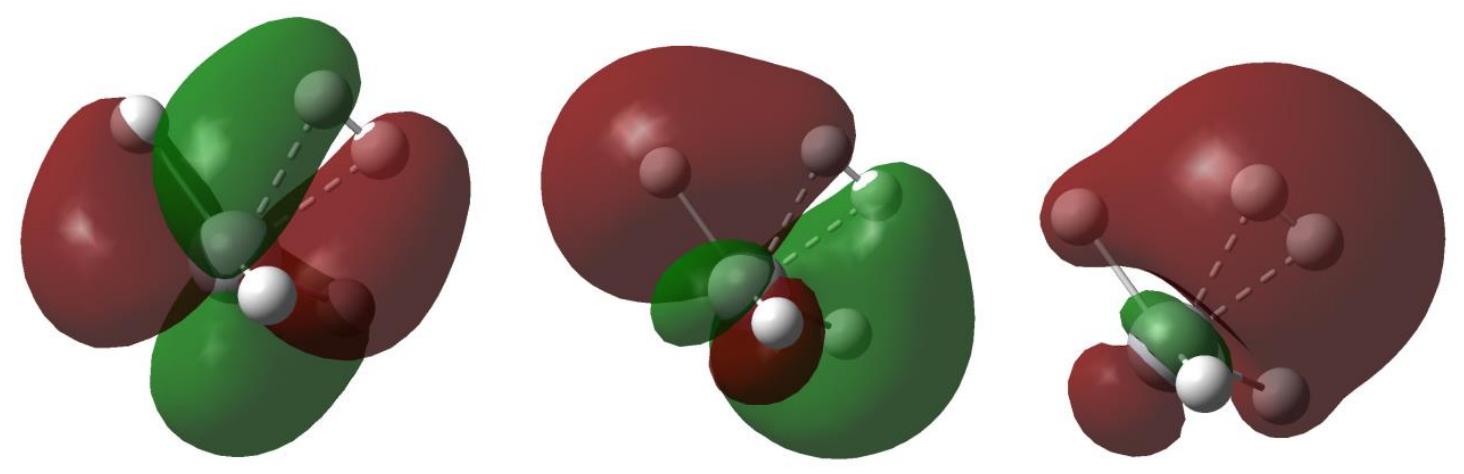

Figure 2. The orbitals involved in the binding of $\mathrm{H}_{2}$ to $\mathrm{VH}_{3}$. Left: $\mathrm{HOMO}-1$, Centre: $\mathrm{HOMO}-3$, and Right: HOMO-5. Isovalue $=0.02$ a.u.

Ball and stick representations of the maximally loaded $\mathrm{MH}_{3}$ systems are shown in figure 3. At the maximum loading level, the $\mathrm{VH}_{3}$ and $\mathrm{CrH}_{3}$ units are now planar, $\mathrm{C}_{2 v}$, with two co-planar $\mathrm{H}_{2}$ units and the remaining $\mathrm{H}_{2}$ in "axial" positions. $\mathrm{TiH}_{3}$ remains non-planar, $\mathrm{C}_{s}$; at its maximum loading the hydrides are in plane with each other, and the $\mathrm{H}_{2}$ units are arranged all around the central $\mathrm{TiH}_{3}$ structure. The maximum $\mathrm{H}_{2}$ loading decreases from five for $\mathrm{TiH}_{3}$ to four for $\mathrm{VH}_{3}$ and three/four on $\mathrm{CrH}_{3}$. The geometry of $\mathrm{CrH}_{3}$ changes very significantly as the $\mathrm{H}_{2}$ loading is increased; most notably, at the maximum loading, two of the hydrides come together to an $\mathrm{H}-\mathrm{H}$ distance of $0.917 \AA$, which is within the range that can be considered as dihydrogen complexation, and so we view the final structure as having 
three added $\mathrm{H}_{2}$ with another $\mathrm{H}_{2}$ coming from the base structure itself. The average HBE at the SCF level is greater for all three systems when at a maximum loading than for their singly loaded counterparts, with the greatest change seen for the $\mathrm{Cr}$ system. The increase in HBE is such that even at the Gibbs level both the $\mathrm{V}$ and $\mathrm{Cr}$ systems show weakly favourable binding, although $\Delta G$ for $\mathrm{TiH}_{3} / 5 \mathrm{H}_{2}$ is still very slightly positive (probably because complexation involves the greatest reduction in the number of molecules in this system); the change from SCF to Gibbs level is, again, around $40 \mathrm{~kJ} \mathrm{~mol}^{-1}$.
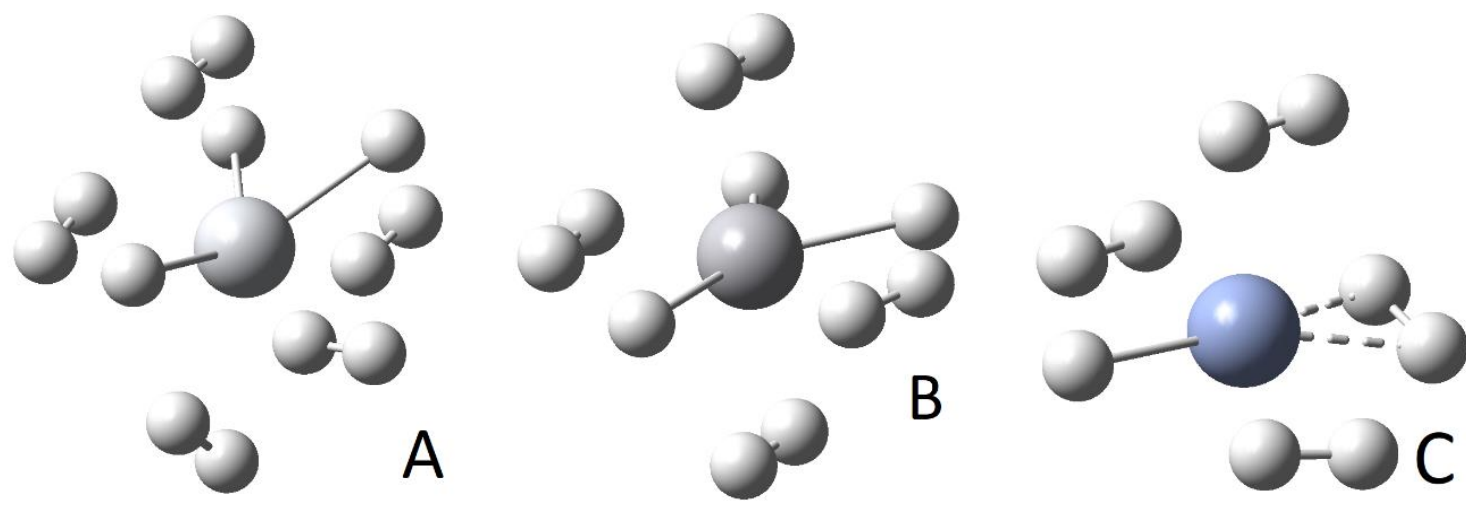

Figure 3. Ball and stick representations of the maximum loading on the $\mathrm{MH}_{3}$ monomers. $A=\mathrm{TiH}_{3}, \mathrm{~B}=$ $\mathrm{VH}_{3}$ and $\mathrm{C}=\mathrm{CrH}_{3}$. The dashed lines in $\mathrm{C}$ indicate the change in the base structure to form a dihydrogen unit.

As with the single $\mathrm{H}_{2}$ case, the average extension of the $\mathrm{H}_{2}$ bond distances (Table 1 ) in the maximally loaded systems does not correlate $\left(R^{2}=0.05\right)$ with stronger binding, as for maximum loading the $\mathrm{Cr}$ system has the greatest average $\mathrm{d}_{\mathrm{H}-\mathrm{H}}$ increase but is not the most strongly binding. There is no longer a strong correlation between the average HBE and the average distance from the metal centre to each $\mathrm{H}_{2}\left(R^{2}=0.53\right)$ although a modest inverse correlation $\left(R^{2}=0.69\right)$ is now seen between $\mathrm{d}_{\mathrm{H}-\mathrm{H}}$ and $\mathrm{d}_{\mathrm{M}-\mathrm{H} 2}$ that is not present in the singly loaded cases. 
The bond lengths and associated stretching frequencies for each $\mathrm{H}_{2}$ on $\mathrm{MH}_{3}$ at the maximum loading level are given in table 2 . The correlation between these two metrics is essentially perfect in all cases. For the $\mathrm{V}$ system there are two pairs of $\mathrm{H}_{2}$; the $\mathrm{H}_{2}$ co-planar with the base structure are the most extended with the lowest stretching frequencies. The two $\mathrm{H}_{2}$ in the $\mathrm{Cr}$ system which have the same bond length are both ones introduced to the base structure, and do not come from changes in the geometry of the base structure upon $\mathrm{H}_{2}$ loading.

Table 2. Individual $\mathrm{H}-\mathrm{H}$ Bond Distances $(\AA)$ and Stretching Frequencies $\left(\mathrm{cm}^{-1}\right)$ for the Maximum Loadings of $\mathrm{H}_{2}$ on $\mathrm{MH}_{3}(\mathrm{M}=\mathrm{Ti}, \mathrm{V}$, and $\mathrm{Cr}) . R^{2}$ data are for the correlation of these two variables.

\begin{tabular}{|c|c|c|c|c|c|c|c|c|c|c|c|}
\hline & $\begin{array}{l}\mathrm{d}_{\mathrm{H}-\mathrm{H}} \\
\mathrm{H}_{2}\end{array}$ & $\begin{array}{l}\text { Stretching } \\
\text { Frequency }\end{array}$ & $R^{2}$ & & $\begin{array}{l}\mathrm{d}_{\mathrm{H}-\mathrm{H}} \\
\mathrm{H}_{2}\end{array}$ & $\begin{array}{l}\text { Stretching } \\
\text { Frequency }\end{array}$ & $R^{2}$ & & $\mathrm{~d}_{\mathrm{H}-\mathrm{H}} \mathrm{H}_{2}$ & $\begin{array}{l}\text { Stretching } \\
\text { Frequency }\end{array}$ & $R^{2}$ \\
\hline \multirow{5}{*}{$\mathrm{Ti}$} & 0.834 & 3077 & \multirow{5}{*}{0.99} & \multirow{5}{*}{ V } & 0.861 & 2782 & \multirow{5}{*}{1.00} & \multirow{5}{*}{$\mathrm{Cr}$} & 0.917 & 2291 & \multirow{5}{*}{1.00} \\
\hline & 0.831 & 3122 & & & 0.861 & 2797 & & & 0.889 & 2530 & \\
\hline & 0.813 & 3335 & & & 0.797 & 3586 & & & 0.889 & 2547 & \\
\hline & 0.810 & 3387 & & & \multirow[t]{2}{*}{0.797} & \multirow[t]{2}{*}{3604} & & & \multirow[t]{2}{*}{0.774} & \multirow[t]{2}{*}{3936} & \\
\hline & 0.799 & 3570 & & & & & & & & & \\
\hline
\end{tabular}

While the monomeric model shows that in principle $\mathrm{MH}_{3}$ can form complexes with $\mathrm{H}_{2}$, the experimental data ${ }^{24-26}$ suggest that these compounds are extended, networked hydrides. It is therefore of interest to explore what happens when these binding sites are part of larger systems, and the next step in our study was to probe the effect of a second metal centre on the binding characteristics. This approach to find more realistic binding sites for $\mathrm{H}_{2}$ on transition metal hydrides has been used in our recent study of $\mathrm{MnH}_{2}$ and its hydrogen storage properties ${ }^{27}$.

$\mathrm{H}_{2}$ binding to $\mathrm{M}_{2} \mathrm{H}_{6}(\mathrm{M}=\mathrm{Ti}, \mathrm{V}, \mathrm{Cr})$ 
The dimeric base structures are shown in figure 4 . They are quite similar to one another with three terminal hydrides and three bridging hydrides. The Ti structure has no mirror plane as the two terminal hydrides that share a metal centre are offset from the Ti-Ti axis. The other two structures have mirror planes through the terminal hydrides and the metals. In the $\mathrm{Cr}$ system the terminal hydrides that share a metal are much closer together than for the other two systems.
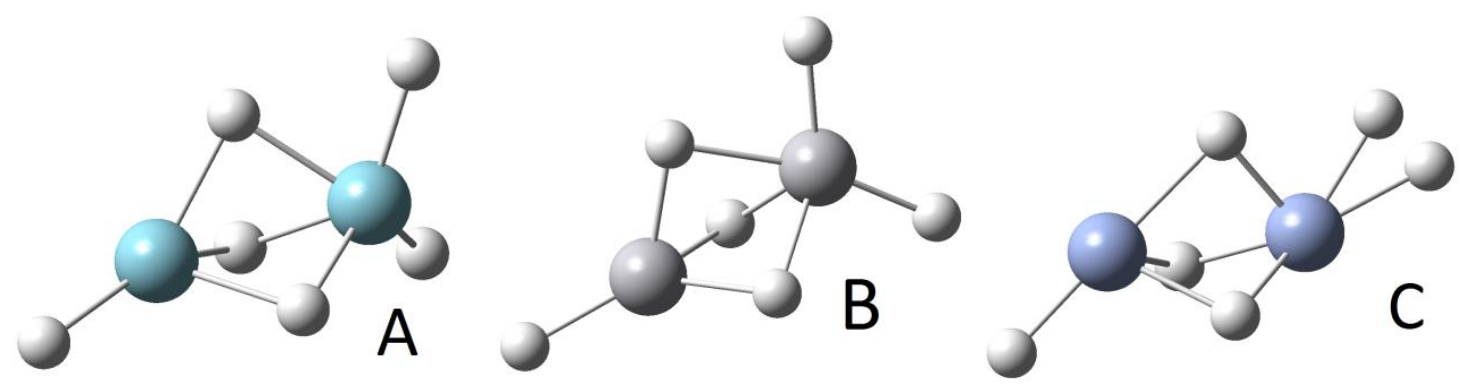

Figure 4. Ball and stick representations of the base structure representations of the $\mathrm{MH}_{3}$ dimers. $\mathrm{A}=\mathrm{Ti}_{2} \mathrm{H}_{6}, \mathrm{~B}=\mathrm{V}_{2} \mathrm{H}_{6}$ and $\mathrm{C}=\mathrm{Cr}_{2} \mathrm{H}_{3}$.

Table 3 contains the hydrogen binding energies and key geometric data for the $\mathrm{M}_{2} \mathrm{H}_{6}$ systems with a single $\mathrm{H}_{2}$ present, as well as the maximum loading level achieved for each metal hydride dimer. At the single $\mathrm{H}_{2}$ loading level the binding energies are larger than those seen on the monomeric systems. For the $\mathrm{M}_{2} \mathrm{H}_{6}$ systems $\mathrm{Cr}$ is the strongest binding at a single loading with $\mathrm{V}$ being the weakest; different from that seen for $\mathrm{MH}_{3}$. Interestingly, in $\mathrm{Cr}_{2} \mathrm{H}_{6}$ a dihydrogen unit is formed from the base structure when a second $\mathrm{H}_{2}$ is introduced, figure 5. This is similar to the maximum loading case for $\mathrm{CrH}_{3}$, although now only one additional $\mathrm{H}_{2}$ is needed to induce this change. As before, the Gibbs energies are much lower, by around $50 \mathrm{~kJ} \mathrm{~mol}^{-1}$, than the $\operatorname{SCF}(\Delta E)$ energies although in all cases the HBG are negative, unlike for the smaller model. 


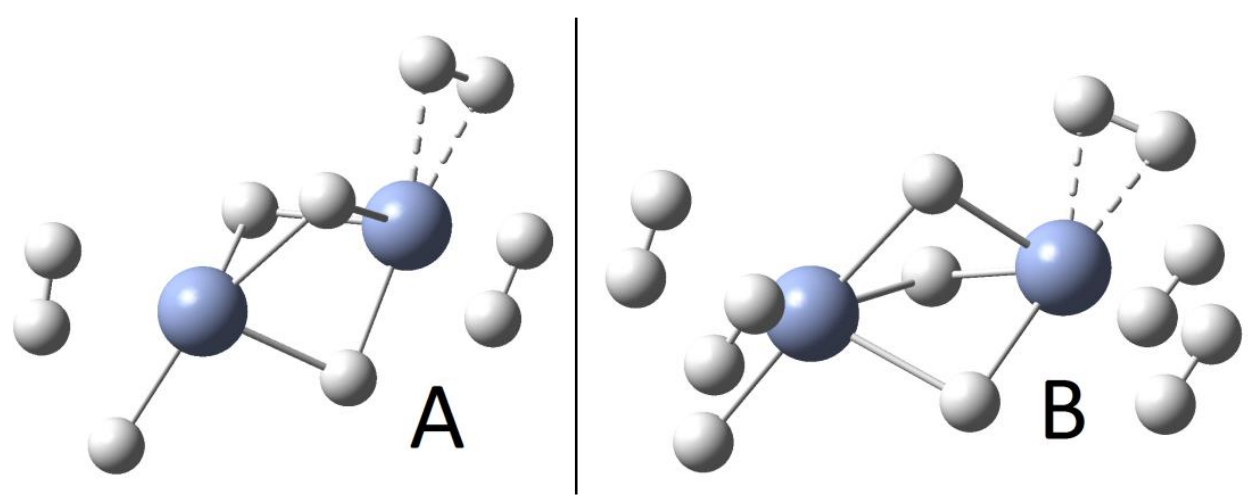

Figure 5. Ball and stick representations of the $\mathrm{CrH}_{3}$ dimers at various $\mathrm{H}_{2}$ loading levels. $A=\mathrm{Cr}_{2} \mathrm{H}_{3} \cdot 2 \mathrm{H}_{2}$, $\mathrm{B}=\mathrm{Cr}_{2} \mathrm{H}_{3} .4 \mathrm{H}_{2}$. The dashed lines indicate the change in the base structure to form a dihydrogen unit.

Table 3. Hydrogen Binging Energies $\left(\mathrm{kJ} \mathrm{mol}^{-1}\right), \mathrm{H}_{2}$ Geometric data $(\AA)$ and Stretching Frequencies $\left(\mathrm{cm}^{-1}\right)$ for $\mathrm{M}_{2} \mathrm{H}_{6}(\mathrm{M}=\mathrm{Ti}, \mathrm{V}, \mathrm{Cr})$

\begin{tabular}{|c|c|c|c|c|c|c|}
\hline Metal & Number of $\mathrm{H}_{2}$ & $\begin{array}{l}\text { Average } \\
\mathrm{HBE}, \Delta E\end{array}$ & $\begin{array}{l}\text { Average } \mathrm{HBG}, \\
\Delta G\end{array}$ & $\begin{array}{l}\text { Average } d_{H-H} \\
\mathrm{H}_{2}\end{array}$ & $\begin{array}{l}\text { Average } \\
\mathrm{d}_{\mathrm{M}-\mathrm{H} 2}\end{array}$ & $\begin{array}{l}\text { Stretching } \\
\text { Frequencies }\end{array}$ \\
\hline \multirow{2}{*}{$\mathrm{Ti}$} & 1 & -83.7 & -34.6 & 0.822 & 1.928 & 3229 \\
\hline & 6 & -51.7 & -7.1 & 0.822 & 1.946 & Table 4. \\
\hline \multirow{2}{*}{ V } & 1 & -71.0 & -21.7 & 0.872 & 1.776 & 2671 \\
\hline & 5 & -57.5 & -13.0 & 0.818 & 1.865 & Table 4. \\
\hline \multirow{3}{*}{$\mathrm{Cr}$} & $1(2)$ & -97.9 & -50.2 & 0.892 & 1.725 & 2405,2595 \\
\hline & & & & $(0.903,0.881)$ & & \\
\hline & $4(5)$ & -50.6 & -9.4 & 0.825 & 1.871 & Table 4. \\
\hline
\end{tabular}

As before, the complexed $\mathrm{H}_{2}$ bonds are significantly extended, especially for the $\mathrm{V}$ and $\mathrm{Cr}$ systems where the extension is more than $0.1 \AA$ with a single $\mathrm{H}_{2}$ present. The two geometry metrics given in table 3 correlate perfectly $\left(R^{2}=1.00\right)$ i.e. as the $\mathrm{H}_{2}$ move further from the metal centre they are less extended. Neither metric correlates with HBE; for $\mathrm{d}_{\mathrm{H}-\mathrm{H}} R^{2}=0.09$ and for $\mathrm{d}_{\mathrm{M}-\mathrm{H} 2} R^{2}=0.07$. The $\mathrm{H}_{2}$ stretching frequencies correlate perfectly with the lengthening of the bonds $\left(R^{2}=1.00\right)$.

The amount of $\mathrm{H}_{2}$ was increased to the maximum loading which maintains the orientation required for Kubas orbital interaction; however for $\mathrm{Cr}$, as noted above, an additional $\mathrm{H}_{2}$ is formed from the base structure upon addition of $\mathrm{H}_{2}$, figure 5 . As the amount of bound $\mathrm{H}_{2}$ is increased the HBE falls significantly; this is by contrast to the monomeric 
systems but consistent with earlier studies, ${ }^{27}$ with all the metals giving final average HBEs between 50 and $60 \mathrm{~kJ} \mathrm{~mol}^{-1}$. The strength of binding follows the order $\mathrm{V}>\mathrm{Cr}>\mathrm{Ti}$, with $\mathrm{V}$ now binding most strongly, by contrast to when only a single $\mathrm{H}_{2}$ is added; at the Gibbs level the trend is maintained.

The bond lengths and associated stretching frequencies of each $\mathrm{H}_{2}$ on $\mathrm{M}_{2} \mathrm{H}_{6}$ at the maximum loading level are given in table 4 . The $\mathrm{H}_{2}$ bonds are extended in each system suggesting complexation through the Kubas interaction. For each $\mathrm{M}_{2} \mathrm{H}_{6}$ the stretching frequency of $\mathrm{H}_{2}$ is correlated with the distance between $\mathrm{H}_{2}$ and its closest metal centre, and the $\mathrm{H}-\mathrm{H}$ bond length is inversely correlated with both of them; $R^{2}$ values can be found in table 4. Unexpectedly, the average extension in $\mathrm{H}_{2}$ bond length and average distance from the closest metal centre to each $\mathrm{H}_{2}$ are not correlated for the dimer at the maximum loading level $\left(R^{2}=0.03\right)$. The relationship between average bond length and average $\mathrm{HBE}$ is now almost linear for $\mathrm{d}_{\mathrm{H}-\mathrm{H}}\left(R^{2}=0.93\right)$, as expected the more energetically favoured interactions are linked with longer $\mathrm{H}-\mathrm{H}$ bonds. There is very little correlation between the average HBE and average $\mathrm{d}_{\mathrm{M}-\mathrm{H} 2}\left(R^{2}=0.19\right)$.

Table 4. Individual $\mathrm{H}-\mathrm{H}$ bond distances $(\AA)$ and stretching frequencies $\left(\mathrm{cm}^{-1}\right)$ for the maximum loadings of $\mathrm{H}_{2}$ on $\mathrm{M}_{2} \mathrm{H}_{6}(\mathrm{M}=\mathrm{Ti}, \mathrm{V}$, and $\mathrm{Cr}) . R^{2}$ values for correlation between $\mathrm{d}_{\mathrm{H}-\mathrm{H}}$ and $\mathrm{d}_{\mathrm{M}-\mathrm{H} 2}, \mathrm{~d}_{\mathrm{H}-\mathrm{H}}$ and stretching frequency, and $\mathrm{d}_{\mathrm{M}-\mathrm{H} 2}$ and stretching frequency are given in this order. Ti: $0.78,1.00$, and 0.80 . V: 1.00, 1.00, and 1.00. Cr: 0.91, 1.00, and 0.94.

\begin{tabular}{|c|c|c|c|c|c|c|c|c|c|c|c|}
\hline & $\begin{array}{l}d_{H-H} \\
H_{2}\end{array}$ & $\mathrm{~d}_{\mathrm{M}-\mathrm{H} 2}$ & $\begin{array}{l}\text { Stretching } \\
\text { Frequency }\end{array}$ & & $\begin{array}{l}\mathrm{d}_{\mathrm{H}-\mathrm{H}} \\
\mathrm{H}_{2}\end{array}$ & $\mathrm{~d}_{\mathrm{M}-\mathrm{H} 2}$ & $\begin{array}{l}\text { Stretching } \\
\text { Frequency }\end{array}$ & & $\begin{array}{l}\mathrm{d}_{\mathrm{H}-\mathrm{H}} \\
\mathrm{H}_{2}\end{array}$ & $\mathrm{~d}_{\mathrm{M}-\mathrm{H} 2}$ & $\begin{array}{l}\text { Stretching } \\
\text { Frequency }\end{array}$ \\
\hline \multirow{6}{*}{$\mathrm{Ti}$} & 0.852 & 1.912 & 2855 & \multirow{6}{*}{ V } & 0.832 & 1.827 & 3123 & \multirow{6}{*}{$\mathrm{Cr}$} & 0.875 & 1.732 & 2643 \\
\hline & 0.833 & 1.910 & 3087 & & 0.826 & 1.839 & 3204 & & 0.865 & 1.752 & 2734 \\
\hline & 0.824 & 1.932 & 3207 & & 0.826 & 1.839 & 3206 & & 0.807 & 1.888 & 3440 \\
\hline & 0.819 & 1.935 & 3263 & & 0.810 & 1.883 & 3413 & & 0.799 & 1.912 & 3539 \\
\hline & 0.813 & 1.951 & 3350 & & 0.794 & 1.936 & 3635 & & 0.779 & 2.071 & 3850 \\
\hline & 0.793 & 2.034 & 3619 & & & & & & & & \\
\hline Avg. & 0.822 & 1.946 & & Avg. & 0.818 & 1.865 & & Avg. & 0.825 & 1.871 & \\
\hline
\end{tabular}

\section{$\mathrm{H}_{2}$ binding to $\mathrm{M}_{5} \mathrm{H}_{15}(\mathrm{M}=\mathrm{Ti}, \mathrm{V})$ and $\mathrm{Cr}_{5} \mathrm{H}_{11}$}


The systems discussed thus far show that the early transition metal hydrides can interact with $\mathrm{H}_{2}$ in a Kubas like fashion to produce dihydrogen complexes. We now progress to larger metal hydride networks, specifically those containing five metals, chosen in part as this is the system size we used in our previous study of $\mathrm{H}_{2}$ binding to a Mn hydride.

Representations of the pentameric base structures are given in figure 6 . All of the structures are networks of mainly bridging and some terminal hydrides. The Ti base structure has five terminal hydrides, two of which are located on the same metal centre. $\mathrm{V}_{5} \mathrm{H}_{15}$ has a similar structure to that of $\mathrm{Ti}_{5} \mathrm{H}_{15}$ with five terminal hydrides. However, performing a geometry optimisation of $\mathrm{Cr}_{5} \mathrm{H}_{15}$ yields the structure shown in figure 6C; two $\mathrm{H}_{2}$ units are generated, similar to the $\mathrm{CrH}_{3}$ and $\mathrm{Cr}_{2} \mathrm{H}_{6}$ structures discussed above, and we take the $\mathrm{Cr}$ base structure with five metal centres to be $\mathrm{Cr}_{5} \mathrm{H}_{11}$, figure $6 \mathrm{D}$. $\mathrm{H}_{2}$ binding calculations are performed on this revised base structure.
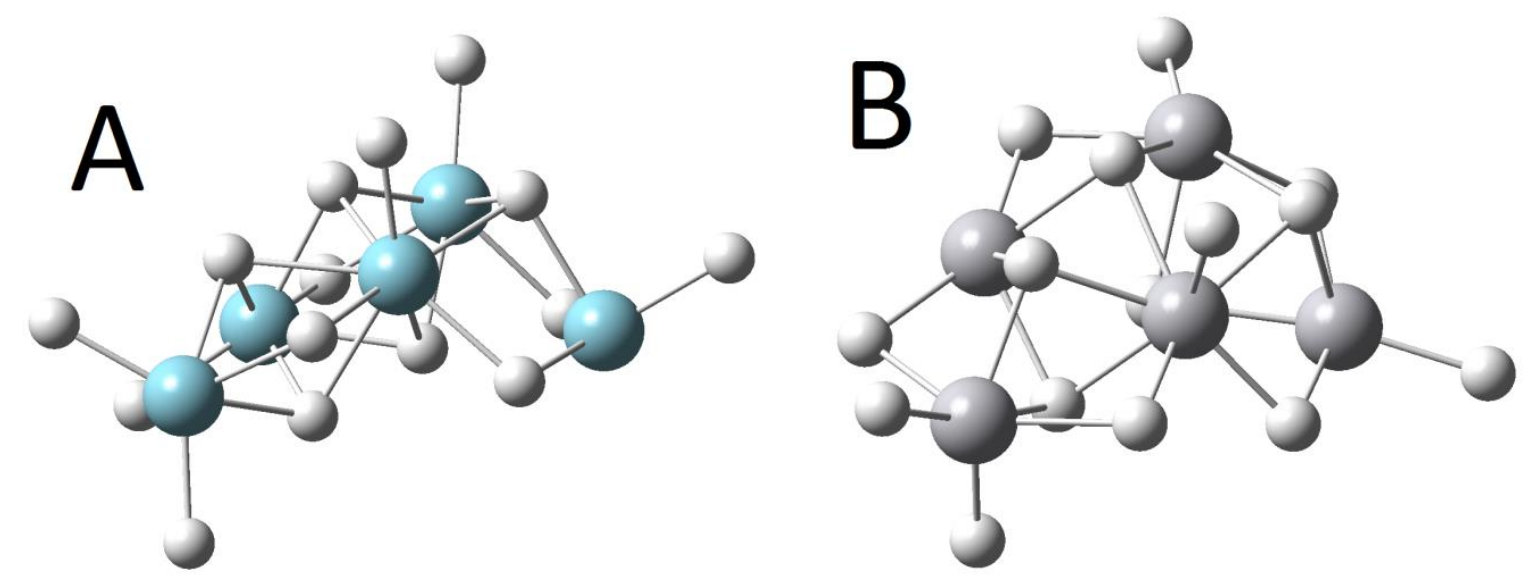

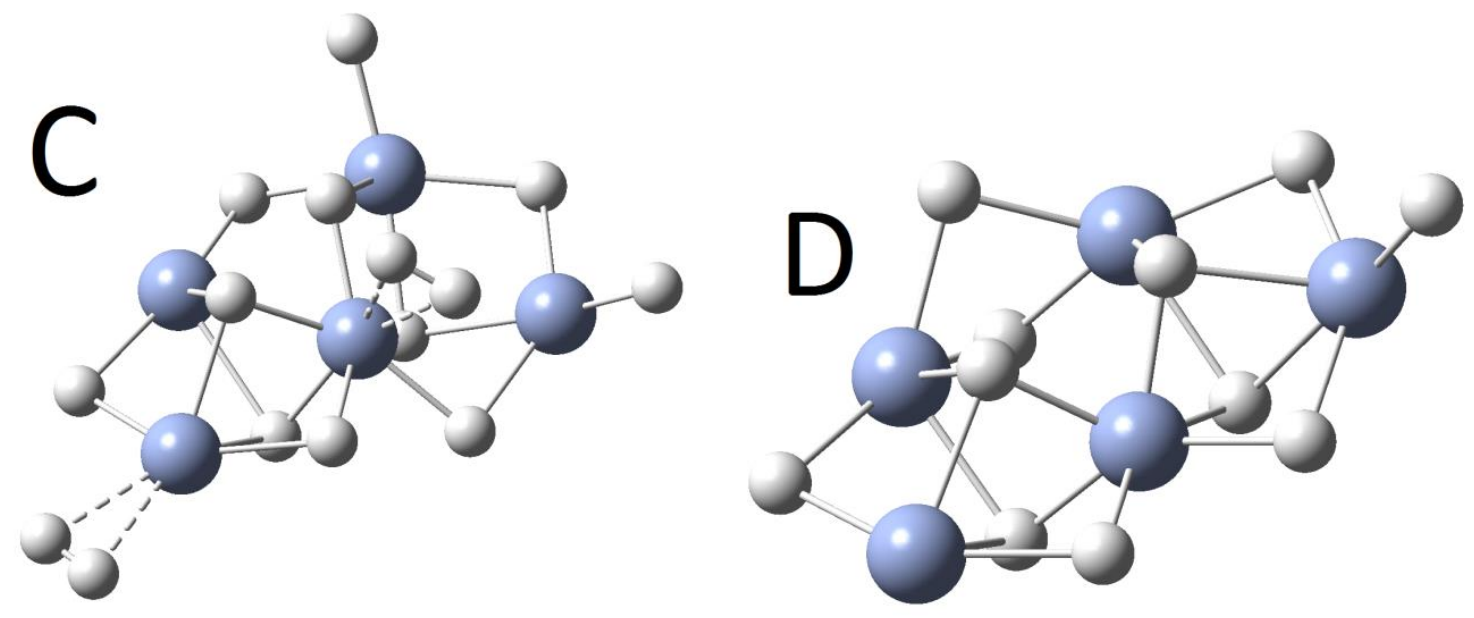

Figure 6. Ball and stick representations of $A=\mathrm{Ti}_{5} \mathrm{H}_{15}, \mathrm{~B}=\mathrm{V}_{5} \mathrm{H}_{15}, \mathrm{C}=\mathrm{Cr}_{5} \mathrm{H}_{15}$ and $\mathrm{D}=\mathrm{Cr}_{5} \mathrm{H}_{11}$. Dashed lines show the $\mathrm{H}_{2}$ units formed from the base structure.

Each system was investigated at loading levels of $1 \mathrm{H}_{2}$ per $M$ and $2 \mathrm{H}_{2}$ per $M$. The maximum loading level was then established as discussed in the Methodology. Then, the maximum loading in which the $\mathrm{H}_{2}$ bind predominantly to the metal centres was determined by removing any $\mathrm{H}_{2}$ that bind closest to the hydrides; this yields the maximum number of $\mathrm{H}_{2}$ which bind in a Kubas manner with the base structure, i.e. we distinguish physisorbed $\mathrm{H}_{2}$ from Kubas-bound $\mathrm{H}_{2}$. The data obtained for each of these loading levels on the five-metal centre systems are collected in table 5.

Table 5. Hydrogen Binding Energies $\left(\mathrm{kJ} \mathrm{mol}^{-1}\right)$ and $\mathrm{H}_{2}$ Geometries $(\AA ̊)$ for $\mathrm{M}_{5} \mathrm{H}_{15}(\mathrm{M}=\mathrm{Ti}, \mathrm{V})$ and $\mathrm{Cr}_{5} \mathrm{H}_{11}$

\begin{tabular}{|c|c|c|c|c|c|}
\hline Metal & Number of $\mathrm{H}_{2}$ & Average $\mathrm{HBE}, \Delta E$ & Average $\mathrm{HBG}, \Delta G$ & $\begin{array}{l}\text { Average } \\
\mathrm{d}_{\mathrm{H}-\mathrm{H}} \mathrm{H}_{2}\end{array}$ & $\begin{array}{l}\text { Average } \\
\mathrm{d}_{\mathrm{M}-\mathrm{H} 2}\end{array}$ \\
\hline \multirow{4}{*}{$\mathrm{Ti}$} & 5 & -43.1 & -1.9 & 0.809 & 1.991 \\
\hline & 10 & -34.1 & 6.1 & 0.805 & 2.156 \\
\hline & $\begin{array}{r}\text { Maximum Bound to } \\
\text { Metal Centres:9 }\end{array}$ & -37.1 & 4.8 & 0.811 & 1.982 \\
\hline & $\begin{array}{r}\text { Maximum Bound to } \\
\text { Base Structure:15 }\end{array}$ & -25.0 & 9.5 & 0.788 & 2.770 \\
\hline \multirow{4}{*}{ V } & 5 & -53.6 & -11.1 & 0.842 & 1.857 \\
\hline & 10 & -32.9 & 4.7 & 0.805 & 2.389 \\
\hline & $\begin{array}{r}\text { Maximum Bound to } \\
\text { Metal Centres:7 }\end{array}$ & -44.6 & -1.3 & 0.832 & 1.852 \\
\hline & $\begin{array}{r}\text { Maximum Bound to } \\
\text { Base Structure:13 }\end{array}$ & -26.8 & 7.8 & 0.793 & 2.712 \\
\hline $\mathrm{Cr}$ & 5 & -46.0 & -2.8 & 0.850 & 1.776 \\
\hline
\end{tabular}




\begin{tabular}{rrrrr}
10 & -25.5 & 6.6 & 0.802 & 2.695 \\
$\begin{array}{r}\text { Maximum Bound to } \\
\text { Metal Centres: } 5\end{array}$ & \multicolumn{5}{c}{ As Above } \\
$\begin{array}{r}\text { Maximum Bound to } \\
\text { Base Structure:12 }\end{array}$ & -22.6 & 9.1 & 0.793 & 2.690
\end{tabular}

$\mathrm{Ti}_{5} \mathrm{H}_{15}$ with $1 \mathrm{H}_{2}$ per metal centre binds more strongly to $\mathrm{H}_{2}$ than the analogous $\mathrm{TiH}_{3}$ monomer (Table 1) with an average $\mathrm{HBE}$ of $43.1 \mathrm{~kJ} \mathrm{~mol}^{-1}$; at the Gibbs level the $\mathrm{H}_{2}$ binding is maintained, unlike in the monomer, but it is now very weak. The HBE suggests that the first $\mathrm{H}_{2}$ per metal centre undergoes a Kubas like orbital interaction with $\mathrm{Ti}$; the extension of $\mathrm{d}_{\mathrm{H}-\mathrm{H}}$ $\mathrm{H}_{2}$ by $0.057 \AA$ is also evidence of this interaction, although this lengthening is smaller than for the analogous $\mathrm{MH}_{3}$ system. Moving to two $\mathrm{H}_{2}$ per metal centre reduces the average $\mathrm{HBE}$ by $9.0 \mathrm{~kJ} \mathrm{~mol}^{-1}$ and becomes non-binding at the Gibbs level; the average extension of the $\mathrm{H}_{2}$ units is slightly reduced.

Table 6 shows the bond lengths, distances from the closest metal centre, and stretching frequency for each dihydrogen in these systems. The final entry for $10 \mathrm{H}_{2}$ on $\mathrm{Ti}_{5} \mathrm{H}_{15}$ is distinctly different as it is much further away from its nearest metal centre, has almost no extension in the $\mathrm{H}-\mathrm{H}$ bond compared with free $\mathrm{H}_{2}$, and has a much higher stretching frequency; these factors point to this $\mathrm{H}_{2}$ being bound in a physisorbed fashion rather than through the Kubas orbital interaction. This physisorbed $\mathrm{H}_{2}$ is the one that is removed to establish the maximum loading in which the $\mathrm{H}_{2}$ bind predominantly to the metal centres (Table 5), discussed above. The maximum loading including physisorption, i.e. the maximum loading of $\mathrm{H}_{2}$ to the whole base structure, not just to the metal centres, is 15 ; this system has a much reduced average $\mathrm{HBE}$ and smaller average $\mathrm{d}_{\mathrm{H}-\mathrm{H}}$ extension as only a subset of the $\mathrm{H}_{2}$ bind in a Kubas manner. A more detailed breakdown of the $\mathrm{H}_{2}$ geometries can be found Table S1, which shows the $9 \mathrm{H}_{2}$ bound in a Kubas fashion and the 6 physisorbed $\mathrm{H}_{2}$. 
$\mathrm{H}_{2}$ on $\mathrm{M}_{5} \mathrm{H}_{15}(\mathrm{M}=\mathrm{Ti}$, and $\mathrm{V})$ and $\mathrm{Cr}_{5} \mathrm{H}_{11}$. Data for maximum bound to base structure can be found in the supplementary information.

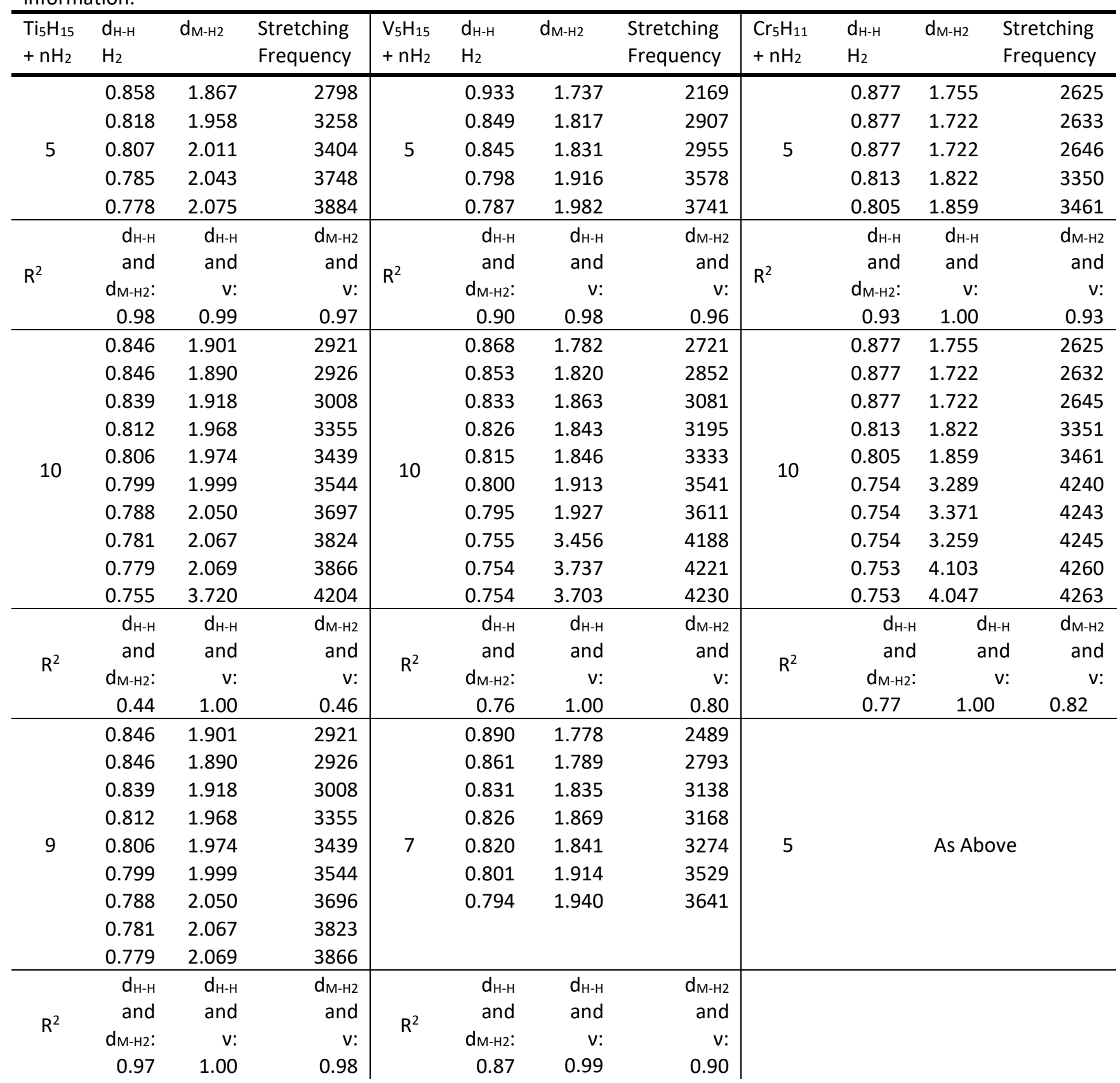

When the $V$ system is extended to include 5 metal centres the $\mathrm{HBE}$ for $1 \mathrm{H}_{2}$ per metal centre increases from the analogous $\mathrm{VH}_{3}$ system by $1.8 \mathrm{~kJ} \mathrm{~mol}^{-1}$, and significant binding is still maintained at the Gibbs level. The extension of the $\mathrm{H}-\mathrm{H}$ bond is also greater than that seen for the $\mathrm{VH}_{3}$ analogue, 0.810 vs $0.842 \AA$; both of these metrics suggest that the complexation of $\mathrm{H}_{2}$ is more favoured on the extended system. When the loading is increased to $2 \mathrm{H}_{2}$ per metal centre the HBE drops significantly and the average $\mathrm{H}_{2}$ extension 
is reduced; this is because there are 3 physisorbed $\mathrm{H}_{2}$ present. When these are removed the average $\mathrm{HBE}$ increases by $11.7 \mathrm{~kJ} \mathrm{~mol}^{-1}$ and the bond extension is increased to only $0.010 \AA$ less than the $1 \mathrm{H}_{2}$ per $V$ system. Including physisorption, the maximum loading is $13 \mathrm{H}_{2}$, Table S1, with 7 Kubas-bound $\mathrm{H}_{2}$ and $6 \mathrm{H}_{2}$ bound via physisorption.

When compared to the $\mathrm{CrH}_{3}$ monomer, the binding for $1 \mathrm{H}_{2}$ per $\mathrm{Cr}$ metal centre shows a large increase in HBE. There is a corresponding large increase in the $\mathrm{H}-\mathrm{H}$ bond extension for the $\mathrm{Cr}_{5} \mathrm{H}_{11}$ system; both metrics indicate stronger Kubas orbital interactions. When an extra $\mathrm{H}_{2}$ is introduced per metal centre there is a dramatic decrease in the average $\mathrm{HBE}$ to about half that at the single $\mathrm{H}_{2}$ loading level, along with a corresponding change in $\mathrm{H}_{2} \mathrm{~d}_{\mathrm{H}-\mathrm{H}}$. This large change is because the second $5 \mathrm{H}_{2}$ all bind to the base structure via physisorption, i.e. the maximum binding to the metal centres via the Kubas mechanism is only $5 \mathrm{H}_{2}$ for this structure. The maximum loading is $12 \mathrm{H}_{2}$ when allowing physisorption, Table S1. More specifically, $6 \mathrm{H}_{2}$ bind via physisorption with the final $\mathrm{H}_{2}$ bound in a fashion in between Kubas and physisorption; its bond length is lengthened $v s$ free $\mathrm{H}_{2}$, but not to the extent of the $5 \mathrm{Kubas}_{2}$. When the physisorbed $\mathrm{H}_{2}$ are included, the average the HBE is lower than for the completely Kubas binding system (with $5 \mathrm{H}_{2}$ ), as expected.

In summary, the pentameric Ti system is able to bind the most $\mathrm{H}_{2}$ through the Kubas mechanism, 9; across the series through $\vee$ to $\mathrm{Cr}$ the maximum amount of Kubas-like $\mathrm{H}_{2}$ decreases by 2 per element. Each system can bind an additional 6 physisorbed $\mathrm{H}_{2}$, and $\mathrm{Cr}_{5} \mathrm{H}_{11}$ adds a further $\mathrm{H}_{2}$ with weak Kubas characteristics, minor extension of the $\mathrm{H}-\mathrm{H}$ bond and a stretching frequency between Kubas like binding and physisorption. $\mathrm{V}_{5} \mathrm{H}_{15}$ binds $\mathrm{H}_{2}$ most strongly.

Figures 7 and 8 show how $d_{H-H} \mathrm{H}_{2}$ correlates with the distance from the metal centre to each $\mathrm{H}_{2}$, and with the stretching frequencies of $\mathrm{H}_{2}$ respectively. The former correlation is 
reasonable, $R^{2}=0.75$, when considering only the Kubas-bound $\mathrm{H}_{2}$. The remaining physiosorbed hydrogen behave differently and cluster together at the left of figure 7 . The relationship between $d_{H-H} H_{2}$ and the stretching frequencies, shown in figure 8 , is linear with an $R^{2}$ value of 0.99 , suggesting that these two factors are indeed very strongly linked.

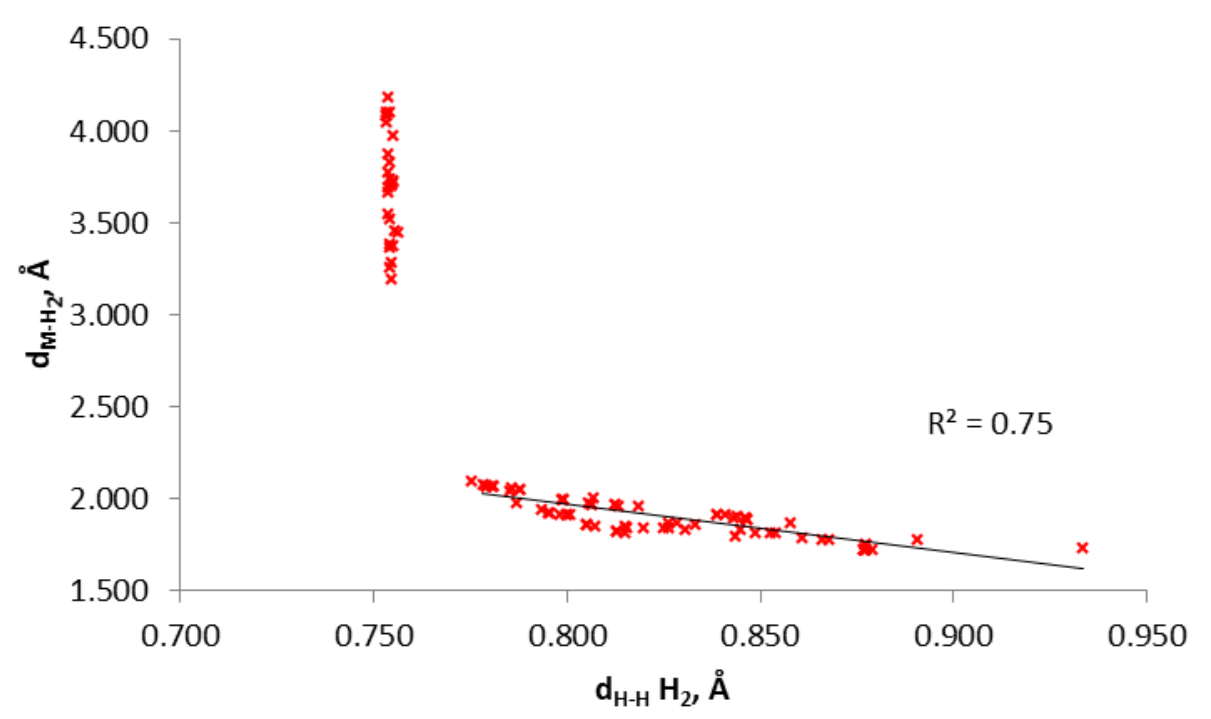

Figure 7. Correlation between $\mathrm{d}_{\mathrm{H}-\mathrm{H}} \mathrm{H}_{2}$ and $\mathrm{d}_{\mathrm{M}-\mathrm{H} 2}$ for the $\mathrm{H}_{2}$ on the 5 metal centre systems; $\mathrm{Ti}_{5} \mathrm{H}_{15}$, $\mathrm{V}_{5} \mathrm{H}_{15}$, and $\mathrm{Cr}_{5} \mathrm{H}_{11}$. This includes every $\mathrm{H}_{2}$ detailed in Tables 6 and $\mathrm{S} 2$, although the $R^{2}$ value is for only the Kubas-bound $\mathrm{H}_{2}$

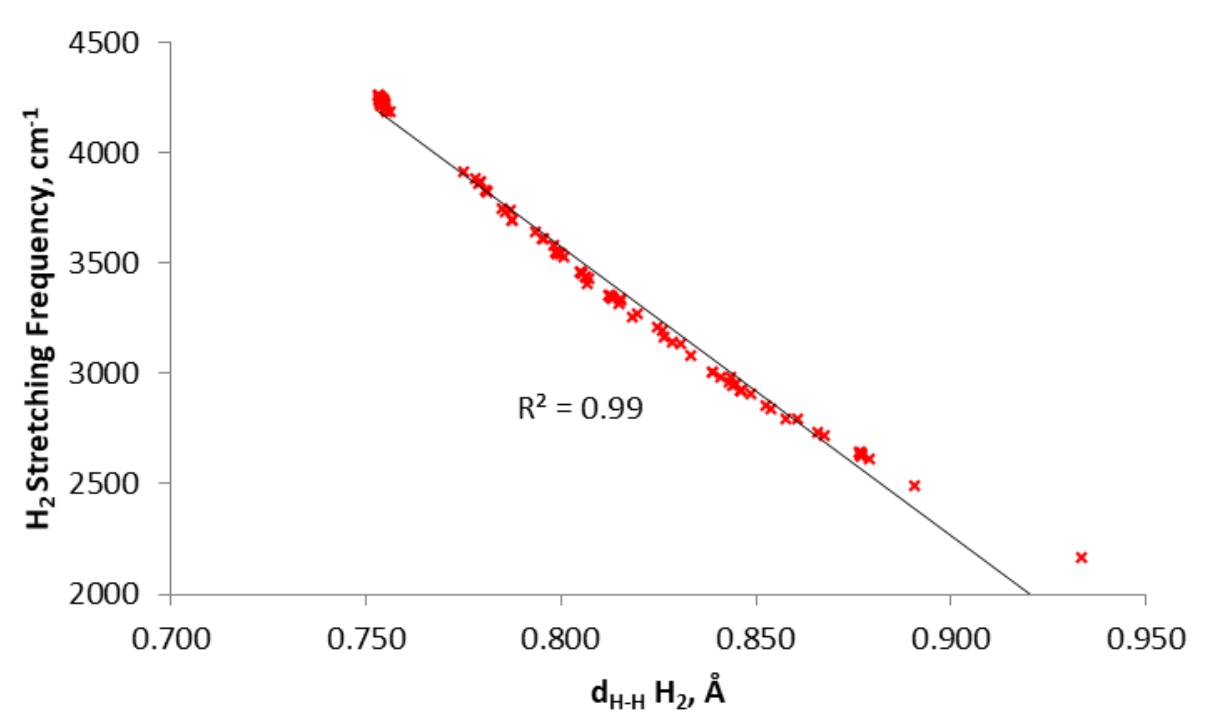

Figure 8. Correlation between $\mathrm{d}_{\mathrm{H}-\mathrm{H}} \mathrm{H}_{2}$ and the stretching frequencies of $\mathrm{H}_{2}$ for the $\mathrm{H}_{2}$ on the 5 metal centre systems; $\mathrm{Ti}_{5} \mathrm{H}_{15}, \mathrm{~V}_{5} \mathrm{H}_{15}$, and $\mathrm{Cr}_{5} \mathrm{H}_{11}$. This includes every $\mathrm{H}_{2}$ detailed in Tables 6 and $\mathrm{S} 2$. 


\section{Comparisons with Our Previous Experimental and Computational Work}

Our previous experimental work on $\mathrm{MH}_{3}{ }^{24-26}$ suggests that each system can bind between 1 and $2 \mathrm{H}_{2}$ per metal centre. This is apparent from the gravimetric adsorption, wt\%, $\mathrm{H}_{2}$ stored for each $\mathrm{MH}_{3}$ system, and the Raman spectra. The experimental data for $\mathrm{TiH}_{3}$ show $3.49 \mathrm{wt} \% \mathrm{H}_{2}$ at 140 bar and $298 \mathrm{~K}^{25}$ which is around $1 \mathrm{H}_{2}$ per metal centre, projected to be $5.8 \mathrm{wt} \%$ when phase pure, which is nearer to $2 \mathrm{H}_{2}$ per Ti. The Raman spectrum for $\mathrm{H}_{2}$-loaded $\mathrm{TiH}_{3}$ at 100 bar shows 3 different Kubas $\mathrm{H}_{2}$ signals at around $3000 \mathrm{~cm}^{-1}$, suggesting multiple binding site types and/or multiple $\mathrm{H}_{2}$ bound to a metal centre; there is negligible physisorbed $\mathrm{H}_{2}$ seen under these conditions. In our $\mathrm{Ti}_{5} \mathrm{H}_{15}$ model we see a loading of 1.8 Kubas bound $\mathrm{H}_{2}$ per metal centre, 6.6 wt\%, a little above that seen experimentally but close to the projected maximum. When physisorbed $\mathrm{H}_{2}$ are included we find a maximum loading of $10.6 \mathrm{wt} \%, 3.0 \mathrm{H}_{2}$ per metal centre, much greater than the ideal projected experimental absorption but, as noted, little physisorbed $\mathrm{H}_{2}$ is seen experimentally. We calculate $\mathrm{H}_{2}$ stretching frequencies at c. $3000 \mathrm{~cm}^{-1}$, as seen experimentally. The experimental heats of adsorption rise as loading of $\mathrm{H}_{2}$ is increased, and is projected to maximise at $32 \mathrm{~kJ} \mathrm{~mol}^{-1}$, very close to the $37.1 \mathrm{~kJ} \mathrm{~mol}^{-1}$ we calculate for just the Kubas bound $\mathrm{H}_{2}$. In general, then, there is good agreement between theory and experiment for this system.

The experimental data for $\mathrm{VH}_{3}$ show a gravimetric storage of $5.8 \mathrm{wt} \%$ at 130 bar and 298 $\mathrm{K}$, which is between 1 and $2 \mathrm{H}_{2}$ per metal centre ${ }^{26}$. This compares well with our calculated Kubas-like maximum; $1.4 \mathrm{H}_{2}$ per centre, $4.9 \mathrm{wt} \%$, but is somewhat lower than the maximum including physisorption; $2.6 \mathrm{H}_{2}$ per centre, $8.8 \mathrm{wt} \%$. The Raman spectrum for $\mathrm{VH}_{3}$ under 100 bar of $\mathrm{H}_{2}$ shows a weak signal at $4105 \mathrm{~cm}^{-1}$ attributed to physisorbed $\mathrm{H}_{2}$ and has 3 other signals, assigned to Kubas-bound $\mathrm{H}_{2}$, at 2770,2929 and $3834 \mathrm{~cm}^{-1}$. We find a range of 
stretching frequencies from 3489 to $3641 \mathrm{~cm}^{-1}$ for Kubas-like $\mathrm{H}_{2}$ along with stretches around $4200 \mathrm{~cm}^{-1}$ for physisorbed $\mathrm{H}_{2}$. Hence the quantitative agreement between theory and experiment for the stretching frequencies is less good than for the Ti system, but qualitatively correct in finding both Kubas and physisorbed $\mathrm{H}_{2}$. By contrast to $\mathrm{TiH}_{3}$, the experimental enthalpy of $\mathrm{H}_{2}$ adsorption is found to be only $0.52 \mathrm{~kJ} \mathrm{~mol}^{-1}$ for $\mathrm{VH}_{3}$, much lower than from our calculations and also lower than that expected for room temperature Kubas binding. This has been attributed ${ }^{28}$ to the material deforming under pressure and thus buffering the energy release of $\mathrm{H}_{2}$ complexation, an effect not accounted for in our computational model. We return to this issue below. This discrepancy is not seen for the Ti case as the heat of adsorption given in that study is a linear extrapolation from much lower loading levels.

$\mathrm{CrH}_{3}$ has a gravimetric storage of $5.08 \mathrm{wt} \% \mathrm{H}_{2}$ at 160 bar and $298 \mathrm{~K}$ which, again, suggests the material binds between 1 and $2 \mathrm{H}_{2}$ per metal centre. ${ }^{24}$ We calculate only $3.6 \mathrm{wt} \%$ of $\mathrm{H}_{2}$ from Kubas binding, rather lower than experiment. When the calculated physisorbed $\mathrm{H}_{2}$ are included we find a gravimetric weight percentage of $8.1 \mathrm{wt} \%$, now well above the experimental value. These data suggest that, like $\mathrm{VH}_{3}$, experiment is measuring both Kubas and physisorbed $\mathrm{H}_{2}$. Consistent with this, the experimental Raman spectrum shows signals at around 4100 to $4200 \mathrm{~cm}^{-1}$, also seen in our models when physisorbed $\mathrm{H}_{2}$ are considered. Raman spectroscopy also finds 3 signals at 2789,2922 and $3188 \mathrm{~cm}^{-1}$ attributed to $\mathrm{H}_{2}$ complexation; we calculate a range of stretching frequencies from 2625 to $3461 \mathrm{~cm}^{-1}$ for Kubas-like $\mathrm{H}_{2}$ suggesting we are finding similar binding motifs. As with $\mathrm{VH}_{3}$, the $\mathrm{Cr}$ system is found experimentally to have a very low adsorption enthalpy, $0.37 \mathrm{~kJ} \mathrm{~mol}^{-1}$, whilst still maintaining $\mathrm{H}_{2}$ binding properties at room temperature. This much lower than expected 
value, which again disagrees with our HBE data, is also attributed to pressure causing the system to distort, buffering the binding energy ${ }^{28}$.

We have previously reported computational work on the $\mathrm{H}_{2}$ binding properties of hydrazide linked systems of $\mathrm{Ti}, \mathrm{V}$ and $\mathrm{Cr},{ }^{28,29}$ studying both $\mathrm{M}(\mathrm{II})$ and $\mathrm{M}(\mathrm{III})$ oxidation states. The $M(I I)$ hydrazide monomers, ${ }^{28}$ with various ancillary ligands including trimethylsilylmethyl, hydrides, hydrazides, and THF, can bind between 1 and $3 \mathrm{H}_{2}$ per metal centre. There is a trend across all the systems in which $\mathrm{Cr}$ binds fewer $\mathrm{H}_{2}$ than $\mathrm{V}$ which in turn binds fewer than Ti; this is the same as we report above for $\mathrm{H}_{2}$ Kubas bound to $\mathrm{MH}_{3}$. The $M(I I)$ hydrazide systems show Kubas like binding, although there is no clear trend as to which metal has the strongest binding; the trends are dependent on the ancillary ligand present. The dimers of the $\mathrm{M}(\mathrm{II})$ hydrazide systems also show no clear binding energy trends across the series, but still display clear Kubas $\mathrm{H}-\mathrm{H}$ bond extension and stretching frequencies.

The trend to fewer Kubas bound $\mathrm{H}_{2}$ across the series is also present in the $\mathrm{M}(\mathrm{III})$ hydrazide dimers, ${ }^{29}$ and once again there is no strong HBE trend at the various loading levels considered. The energies we found for the fully hydrazide based M(III) systems are lower than we observe for the present hydride systems. However, when a hydride is introduced to the Ti(III) hydrazide system there is a large increase in the HBE to a level similar to our hydrides, $-47.83 \mathrm{~kJ} \mathrm{~mol}^{-1}$.

As with the $\mathrm{MH}_{3}$ systems, the structure of these hydrazine systems is thought to distort under pressure of $\mathrm{H}_{2}$, buffering the energy gain of $\mathrm{H}_{2}$ complexation. We previously tested this effect computationally ${ }^{28}$ by determining the energy differences between the base structures before and after the addition of $\mathrm{H}_{2}$, finding a destabilising change in the energy per $\mathrm{H}_{2}$ of between 20.5 and $37.2 \mathrm{~kJ} \mathrm{~mol}^{-1}$ for $\mathrm{V}(\mathrm{III})$ and between 42.2 and $44.6 \mathrm{~kJ} \mathrm{~mol}^{-1}$ for 
$\mathrm{Cr}(\mathrm{II})$. When similar data are obtained for the model $\mathrm{MH}_{3}$ systems under consideration in this study we find an energy difference per $\mathrm{H}_{2}$ in the pentameric base structures before and after attaining maximum Kubas loading of $8.1 \mathrm{~kJ} \mathrm{~mol}^{-1}$ for $\mathrm{Ti}_{5} \mathrm{H}_{15}, 12.6 \mathrm{~kJ} \mathrm{~mol}^{-1}$ for $\mathrm{V}_{5} \mathrm{H}_{15}$ and, $17.7 \mathrm{~kJ} \mathrm{~mol}^{-1}$ for $\mathrm{Cr}_{5} \mathrm{H}_{11}$, which at least qualitatively suggests that a similar buffering/flexing mechanism to that previously proposed is possible for these materials. Since a real world structure would require reordering of bonds in 3 dimensions rather than only 2 dimensions in the modelled pentamers, greater reorganization energies would be expected in reality. 


\section{Conclusions}

In this contribution, we have presented quantum chemical computational evidence that mono- and multi-metallic models of $\mathrm{MH}_{3}(\mathrm{M}=\mathrm{Ti}, \mathrm{V}$, and $\mathrm{Cr})$ can all employ Kubas-like complexation to bind dihydrogen via interaction between the metal d orbitals and the $\mathrm{H}_{2} \sigma$ and $\sigma^{*}$ orbitals. All of the models show a large affinity for $\mathrm{H}_{2}$, with binding energies at the upper end of those expected for such an interaction; each also shows the Kubas motif of extended $\mathrm{H}_{2}$ bond lengths. The experimental energies are much lower than those we calculate, the projected $\mathrm{HBE}$ for $\mathrm{TiH}_{3}$ is of the same magnitude as the calculated value. This energy discrepancy is attributed to flexing of the macro structure, which buffers the energy released by hydrogen binding.

The amount of $\mathrm{H}_{2}$ found to bind to these systems via the Kubas mechanism is consistent with our previous experimental data; between 1 and $2 \mathrm{H}_{2}$ per metal centre. When all our physisorbed $\mathrm{H}_{2}$ are included we find that our models bind more $\mathrm{H}_{2}$ than the experimental systems, with $\mathrm{TiH}_{3}$ binding as many as $3 \mathrm{H}_{2}$ per centre. Qualitatively, however, our models agree well with experiment. Combining data from experiment and computation, we conclude that $\mathrm{TiH}_{3}$ binds almost exclusively via the Kubas interaction, whereas $\mathrm{VH}_{3}$ and $\mathrm{CrH}_{3}$ bind using both Kubas and physisorption. It is likely the extent of the latter which is responsible for the quantitative differences between experiment and theory for the amount of $\mathrm{H}_{2}$ that can bind to $\mathrm{VH}_{3}$ and $\mathrm{CrH}_{3}$, most likely arising from the limitations of a small molecular cluster representation of an extended system.

It has been shown across our previous work, and in this study, that the early transition metals from $\mathrm{Ti}$ to $\mathrm{Mn}$ can bind $\mathrm{H}_{2}$ via the Kubas interaction. We have seen trends across these studies that show that when $\mathrm{Ti}$ binds $\mathrm{H}_{2}$ it achieves a greater maximum loading than the other transition metals across the series. However, the HBEs do not correlate well with 
the maximum loading throughout; similar trends in binding energies have been seen in this work and our previous systems. ${ }^{28,29}$

Consideration of the pentameric models suggests that $\mathrm{VH}_{3}$ would provide the best practical alternative from a cost/performance perspective as it binds $\mathrm{H}_{2}$ the most strongly, while also supporting a significant number of $\mathrm{H}_{2}$ per metal atom, with vanadium costing significantly less than chromium or titanium. The reason that experimental studies have yielded lower values in all three cases is likely related to the lack of convenient metal alkyl precursors and overall control over the decomposition of the metal alkyl into a porous metal hydride with maximum diffusion characteristics and available binding sites. For this reason continued synthetic efforts into this exciting new class of materials are warranted.

\section{Acknowledgments}

The authors acknowledge Hydro Quebec and the University of Manchester for funding. We also thank the Computational Shared Facility (CSF) at the University of Manchester for computational resources and associated support services. 


\section{$\underline{\text { References }}$}

1. P. Jena. Journal of Physical Chemistry Letters, 2011, 2, 206-211.

2. M. Balat, International Journal of Hydrogen Energy, 2008, 33, 4013-4029.

3. J. Ren, H. W. Langmi, B. C. North, M. Mathe, International Journal of Energy Research, 2015, 39, 607.

4. R. von Helmolt, U. Eberle, Journal of Power Sources, 2007, 165, 833.

5. N.A.A. Rusman, M. Dahari, Int. J. Hydrogen Energy, 2016, 41, 12108.

6. L. Schlapbach, A. Züttel. Nature, 2001, 414, 353.

7. D. Durbin, C. Malardier-Jugroot, Int. J. Hydrogen Energy, 2013, 38, 14595.

8. J. M. Simmons, T. Yildirim, A. Hamaed, D. M. Antonelli, M. I. Webb and C. J. Walsby,Chem. Eur. J., 2012 18, 4170-4173

9. M. Dincă, A. F. Yu, \& J. R. Long, Journal of the American Chemical Society, 2006, 128, 8904-8913.

10. M. Dincă, A. F. Yu, \& J. R. Long, Journal of the American Chemical Society, 2005, 127, 9376-9377.

11. M. P. Suh, H. J. Park, T. K. Prasad, \& D. Lim, Chemical Reviews, 2012, 112, 782-835.

12. A. G. Wong-Foy, A. J. Matzger \& O. M. Yaghi, Journal of the American Chemical Society, 2006, 128, 34943495.

13. B. Sakintuna, F. Lamari-Darkrim, M. Hirscher, International Journal of Hydrogen Energy, 2007, 32, 1121

14. B. Bogdanović, M. Schwickardi, Journal of Alloys and Compounds, 1997, 253, 1-9

15. G. J. Kubas, Chem. Rev., 2007, 107, 4152.

16. G. J. Kubas, Journal of Organometallic Chemistry, 2009, 694(17), 2648-2653.

17. , T. K. A. Hoang, \& D. M. Antonelli, Advanced Materials, 2009, 21(18), 1787-1800.

18. G. J. Kubas, C. J. Unkefer, B. I. Swanson \& E. Fukushima, Journal of the American Chemical Society, 1986, 108(22), 7000-7009.

19. P. Atkins and D. Shriver, Inorganic Chemistry, 2010, Oxford University Press, $5^{\text {th }}$ Ed.

20. C. V. J. Skipper, A. Hamaed, D. M. Antonelli, \& N. Kaltsoyannis, Dalton Transactions, 2012, 41(28), 8515-23.

21. C. V. J. Skipper, T. K. A. Hoang, D. M. Antonelli, \& N. Kaltsoyannis, Chem. Eur. J., 2012, 18(6), $1750-60$.

22. A. Hamaed, H. Van Mai, T. K. A. Hoang, M. Trudeau, \& D. Antonelli, The Journal of Physical Chemistry C, 2010, 114(18), 8651-8660.

23. C. V. J. Skipper, A. Hamaed, D. M. Antonelli, \& N. Kaltsoyannis, Journal of the American Chemical Society, 2010, 132(48), 17296-305.

24. L. Morris, M. L. Trudeau, D. Reed, D. Book, D. M. Antonelli, Phys. Chem. Chem. Phys., 2015, 17, 9480.

25. T. K. A. Hoang, L. Morris, D. Reed, D. Book, M. L. Trudeau, \& D. M. Antonelli, Chemistry of Materials, 2013, 25, 4765-4771.

26. L. Morris, L. A. C. Smith, M. L. Trudeau, D. M.Antonelli J. Phys. Chem C,.2016, 120, 11407-11414.

27. L. Morris, J. J. Hales, M. L. Trudeau, P. Georgiev, J. P. Embs, J. Eckert, N. Kaltsoyannis and D. M. Antonelli, Energy and Environmental Science, 2019, DOI: 10.1039/c8ee02499e

28. C. V. J. Skipper, D. M. Antonelli, \& N. Kaltsoyannis, The Journal of Physical Chemistry C, 2012, 116(36), 19134-19144.

29. C. V. J. Skipper, A. Hamaed, D. M. Antonelli, \& N. Kaltsoyannis, Dalton Transactions, 2012, 41(28), 8515-23.

30. C. V. J. Skipper, T. K. A. Hoang, D. M. Antonelli, \& N. Kaltsoyannis, Chem. Eur. J., 2012, 18(6), 1750-60.

31. J. P. Perdew, K. Burke, M. Erzerhof, Physical Review Letters, 1996, 77, 3865.

32. J. P. Perdew, K. Burke, M. Erzerhof, Physical Review Letters, 1997, 78, 1396.

33. S. Grimme, J. Antony, S. Ehrlich, H. Krieg, The Journal of Chemical Physics, 2010, 132, 154104.

34. A. J. H. Wachters, The Journal of Chemical Physics, 1970, 52(3), 1033.

35. P. J. Hay, The Journal of Chemical Physics, 1977, 66(10), 4377.

36. A. D. McLean, \& G. S. Chandler, The Journal of Chemical Physics, 1980, 72(10), 5639.

37. R. Krishnan, J. S. Binkley, R. Seeger, \& J. A. Pople, The Journal of Chemical Physics, 1980, 72(1), 650.

38. E. Tsivion, J. R. Long, \& M. Head-Gordon, Journal of the American Chemical Society, 2012, 136, 1782717835.

39. R. C. Lochan, \& M. Head-gordon, Physical Chemistry Chemical Physics, 2006, 8, 1357-1370. 
40. M. Kocman, P. Jurečka, M. Dubecký, M. Otyepka, Y. Cho and K. S. Kim, Physical Chemistry Chemical Physics, 2015, 17, 6423.

41. J. Gebhardt, F. Viñes, P. Bleiziffer, W. Hieringer, A. Görling, Physical Chemistry Chemical Physics, 2015, 16, 5382-5392.

42. A. Mavrandonakis, K. D. Vogiatzis, A. D. Boese, K. Fink, T. Heine, W. Klopper. Inorganic Chemistry, 2015, 54, 8251-8263.

43. M. Manadé, F. Viñes, A. Gil, F.Illas. Physical Chemistry Chemical Physics, 2018, 20, 3819-3830.

44. Gaussian 09, Revision D.01, M. J. Frisch, G. W. Trucks, H. B. Schlegel, G. E. Scuseria, M. A. Robb, J. R. Cheeseman, G. Scalmani, V. Barone, B. Mennucci, G. A. Petersson, H. Nakatsuji, M. Caricato, X. Li, H. P. Hratchian, A. F. Izmaylov, J. Bloino, G. Zheng, J. L. Sonnenberg, M. Hada, M. Ehara, K. Toyota, R. Fukuda, J. Hasegawa, M. Ishida, T. Nakajima, Y. Honda, O. Kitao, H. Nakai, T. Vreven, J. A. Montgomery, Jr., J. E. Peralta, F. Ogliaro, M. Bearpark, J. J. Heyd, E. Brothers, K. N. Kudin, V. N. Staroverov, R. Kobayashi, J. Normand, K. Raghavachari, A. Rendell, J. C. Burant, S. S. Iyengar, J. Tomasi, M. Cossi, N. Rega, J. M. Millam, M. Klene, J. E. Knox, J. B. Cross, V. Bakken, C. Adamo, J. Jaramillo, R. Gomperts, R. E. Stratmann, O. Yazyev, A. J. Austin, R. Cammi, C. Pomelli, J. W. Ochterski, R. L. Martin, K. Morokuma, V. G. Zakrzewski, G. A. Voth, P. Salvador, J. J. Dannenberg, S. Dapprich, A. D. Daniels, Ö. Farkas, J. B. Foresman, J. V. Ortiz, J. Cioslowski, and D. J. Fox, Gaussian, Inc., Wallingford CT, 2009.

45. Gaussian 16, Revision B.01, M. J. Frisch, G. W. Trucks, H. B. Schlegel, G. E. Scuseria, M. A. Robb, J. R. Cheeseman, G. Scalmani, V. Barone, G. A. Petersson, H. Nakatsuji, X. Li, M. Caricato, A. V. Marenich, J. Bloino, B. G. Janesko, R. Gomperts, B. Mennucci, H. P. Hratchian, J. V. Ortiz, A. F. Izmaylov, J. L. Sonnenberg, D. Williams-Young, F. Ding, F. Lipparini, F. Egidi, J. Goings, B. Peng, A. Petrone, T. Henderson, D. Ranasinghe, V. G. Zakrzewski, J. Gao, N. Rega, G. Zheng, W. Liang, M. Hada, M. Ehara, K. Toyota, R. Fukuda, J. Hasegawa, M. Ishida, T. Nakajima, Y. Honda, O. Kitao, H. Nakai, T. Vreven, K. Throssell, J. A. Montgomery, Jr., J. E. Peralta, F. Ogliaro, M. J. Bearpark, J. J. Heyd, E. N. Brothers, K. N. Kudin, V. N. Staroverov, T. A. Keith, R. Kobayashi, J. Normand, K. Raghavachari, A. P. Rendell, J. C. Burant, S. S. Iyengar, J. Tomasi, M. Cossi, J. M. Millam, M. Klene, C. Adamo, R. Cammi, J. W. Ochterski, R. L. Martin, K. Morokuma, O. Farkas, J. B. Foresman, and D. J. Fox, Gaussian, Inc., Wallingford CT, 2016. 